\title{
ANÁlISE QUíMICA DA MADEIRA E CASCA DE DIFERENTES TIPOS DE EUCALIPTO ANTES E DURANTE O CULTIVO DE SHIITAKE EM TORAS ${ }^{1}$
}

Meire Cristina Nogueira de Andrade ${ }^{2}$, Marli Teixeira de Almeida Minhoni ${ }^{3}$ Cláudio Angeli Sansígolo ${ }^{4}$ e Diego Cunha Zied ${ }^{3}$

\begin{abstract}
RESUMO - Avaliaram-se a composição química da madeira e da casca de sete espécies (E. saligna, E. grandis, E. urophylla, E. camaldulensis, E. citriodora, E. paniculata e E. pellita) e três clones de eucalipto (híbridos de E. grandis x E. urophylla), antes e durante o cultivo das linhagens LE-95/01 e LE-96/18 de shiitake (Lentinula edodes), em toras. Cada linhagem de shiitake foi inoculada em nove toras de cada tipo de eucalipto com 1 m de comprimento e 9 a $14 \mathrm{~cm}$ de diâmetro. Assim, o delineamento experimental foi inteiramente casualizado, com 20 tratamentos e nove repetições, sendo cada repetição correspondente a uma tora. As toras foram mantidas em estufa climatizada, com temperatura de $25^{\circ} \mathrm{C} \pm 5$ e umidade relativa do ar entre $60-80 \%$, durante 12 meses. Para a determinação da composição química da madeira, analisaram-se cunhas de discos e cascas de eucalipto recém-cortadas (sem inoculação das linhagens de L. edodes) e cunhas de discos e cascas retirados de toras já inoculadas com as linhagens de L. edodes após oito meses de incubação. Os resultados mostraram diferenças nos teores de holocelulose, lignina e extrativos totais na madeira e casca após o corte e depois de oito meses de incubação nas espécies e clones de eucalipto; o maior índice de decomposição da holocelulose na madeira, ao longo do tempo, ocorreu no E. saligna $(5,5 \%)$, indicando, assim, ser o mais favorável para o desenvolvimento micelial do L. edodes. Já na casca aconteceu no clone $24(22,2 \%)$. O E. camaldulensis apresentou o maior índice de decomposição da lignina na madeira $(6,8 \%)$, ao longo do tempo. Já na casca, entre os eucaliptos testados, o E. grandis sofreu a maior decomposição de lignina (21,9\%); o L. edodes degradou muito mais a holocelulose e lignina da casca que da madeira, tornando evidente a importância da casca; a casca da maioria dos tipos de eucaliptos apresentou menor teor de holocelulose, maior teor de extrativos totais e teores de lignina semelhantes ou superiores quando comparados com a madeira. $\mathrm{O}$ fator tipo de eucalipto (espécies e clones) teve maior efeito que o fator linhagem de L. edodes na degradação da holocelulose e lignina.
\end{abstract}

Palavras-chave: Lentinula edodes, Cogumelos e composição química da madeira.

\section{CHEMICAL ANALYSIS OF THE WOOD AND BARK OF DIFFERENT EUCALYPTUS TYPES BEFORE AND DURING THE SHIITAKE CULTIVATION}

\begin{abstract}
Chemical composition of the wood and bark of seven eucalyptus species (E. saligna, E. grandis, E. urophylla, E. camaldulensis, E. citriodora, E. paniculata and E. pellita) and three eucalyptus clones (E. grandis $x$ E. urophylla hybrids) were evaluated before and during log cultivation of shiitake (Lentinula edodes) strains LE-95/O1 and LE-96/18. Each shiitake strain was inoculated into 9 logs, $1 \mathrm{~m}$ in length and 9 to 14 $\mathrm{cm}$ in diameter, of each type of eucalyptus. The experimental design was complete randomized, with 20 treatments and 9 repetitions, with each log corresponding to a repetition. Logs were kept in a greenhouse, at $25^{\circ} \mathrm{C}$ \pm 5 and relative air humidity between 60-80\%, for 12 months. Chemical composition was determined in newly cut disks and barks wedges of eucalyptus (without inoculation of L. edodes strains) and disks wedges removed from inoculated logs after 8 of incubation. Results showed differences in holocelluose, lignin and total extractives contents in wood and bark after cutting and after 8 months of incubation in the eucalypt species and clones. The highest hollocelullose decomposition rate in wood, over the time, occurred in $\mathrm{E}$. saligna $(5.5 \%)$, pointing out this species as the most favorable for micelial development of $\mathrm{L}$. edodes, whereas
\end{abstract}

\footnotetext{
${ }^{1}$ Recebido em 27.08.2007 e aceito para publicação em 14.010.2009.

${ }^{2}$ Instituto Nacional de Pesquisas da Amazônia, Coordenação de Pesquisas de Produtos Florestais - Manaus, AM - Brasil E-mail: <mcnandrade@ @otmail.com>.

${ }^{3}$ Universidade Estadual Paulista Júlio de Mesquita Filho, Faculdade de Ciências Agronômicas de Botucatu, Departamento de Produção Vegetal - Botucatu, SP - Brasil E-mail: <marliminhoni@fca.unesp.br>e <dczied@ @ca.unesp.br>.

${ }^{4}$ Universidade Estadual Paulista Júlio de Mesquita Filho, Faculdade de Ciências Agronômicas de Botucatu, Departamento de Recursos Naturais - Botucatu, SP E-mail: <sansigolo@fca.unesp.br>.
} 
for bark, it occurred in clone $24(22.2 \%)$. E. camaldulensis presented the highest lignin decomposition rate in wood (6.8\%), over the time. Bark of $\mathrm{E}$. grandis showed the highest lignin decomposition (21.9\%) among the tested eucalyptus. L. edodes degraded more holocellulose and lignin from bark than from wood, indicating the importance of this material. Bark of most eucalyptus types showed lower holocelluose content, higher total extractive content and lignin contents similar or higher compared with wood. The factor eucalypt type (species or clones) showed higher effect than L. edodes strains on degradation of holocelluose and lignin.

Keywords: Lentinula edodes, Mushrooms and wood chemical composition.

\section{INTRODUÇÃO}

O gênero Eucalyptus possui variabilidade genética elevada. São centenas de espécies com propriedades físicas e químicas tão diversas que fazem que os eucaliptos sejam utilizados para as mais diversas finalidades (SILVA, 2003). Apesar de a maior parte das florestas estarem comprometida com a produção de madeira para os denominados "usos tradicionais" (celulose e papel, carvão vegetal, lenha e painéis de madeira), o eucalipto também vem sendo utilizado com sucesso para a produção do shiitake [Lentinula edodes Berk. (Pegler)] (ANDRADE, 2007; ANDRADE e GRACIOLLI, 2005; MONTINI, 1997; QUEIROZ, 2002; TEIXEIRA, 2000).

Os principais fatores que podem interferir na produção do shiitake em toras são: linhagem do fungo, tipo de madeira, diâmetro das toras, condições climáticas, fungos competidores e os métodos de manejo (ANDRADE et al.; 2007; CHEN, 2005).

Com relação às características químicas, estas variam com os tecidos da madeira, de modo que a distribuição dos compostos químicos é heterogênea, como resultado da estrutura anatômica da planta. Cada componente está presente em quantidades específicas (TREVISAN et al., 2007; SOUZA et al., 1979) e possui características bem definidas, as quais podem ser influenciadas pelas condições a que a madeira está submetida (BROWNING, 1963). Assim, para o cultivo do shiitake recomenda-se que as árvores sejam obtidas, preferencialmente de áreas adubadas e que sejam de primeiro ou de segundo corte (TOKIMOTO, 2005; PRZYBYLOWICZ e DONOGHUE, 1990; EIRA e MONTINI, 1997). Também, há grande variabilidade na produção do shiitake em função das espécies de eucalipto, mesmo que provenientes de povoamentos que tiveram adubação em seu manejo, sendo tais resultados função das características químicas e físicas de cada espécie utilizada (TEIXEIRA, 2000).

R. Árvore, Viçosa-MG, v.34, n.1, p.165-175, 2010
As propriedades químicas e físicas de diferentes espécies de eucalipto foram bem estudadas para a produção de celulose Kraft, conforme mostrado nos trabalhos de Foelkel et al. (1975), Barrichelo e Brito (1976), Barrichelo e Foelkel (1976) e Gonzaga et al. (1983).

Assim, este estudo teve como objetivo analisar a composição química da madeira e da casca de sete espécies e três clones de eucalipto antes e durante o cultivo de shiitake.

\section{MATERIAL E MÉTODOS}

O experimento foi conduzido nas dependências do Departamento de Produção Vegetal da Faculdade de Ciências Agronômicas (FCA) da Universidade Estadual Paulista (UNESP), localizada na Fazenda Experimental Lageado, Campus de Botucatu, SP.

As espécies de eucalipto utilizadas nos experimentos foram: E. saligna, E. grandis, E. urophylla, E. camaldulensis, E. citriodora, E. paniculata e E. pellita. Os clones, por sua vez, foram híbridos de $E$. grandis $\mathrm{x}$ E. urophylla, desenvolvidos por duas empresas de celulose e papel e identificados como clones 23,24 e 25. Tanto as espécies quanto os clones de eucalipto foram obtidos na Estação Experimental de Ciências Florestais, ESALQ/ USP, Itatinga, SP. As árvores utilizadas tinham 8 anos de idade e foram retiradas de uma mesma área de plantio, cultivadas em Latossolo Vermelho-Amarelo, no espaçamento de 3,0 x 1,8 m.

As linhagens de L. edodes utilizadas foram LE95/01 e LE-96/18, as quais se encontravam armazenadas (conservadas em óleo mineral) na Micoteca do Módulo de Cogumelos, localizado no Departamento de Produção Vegetal da Faculdade de Ciências Agronômicas da UNESP de Botucatu, SP.

O delineamento experimental foi inteiramente casualizado em esquema fatorial 2 x 10, correspondente a duas linhagens de L. edodes e 10 tipos de eucalipto 
(7 espécies e 3 clones). Foram 20 tratamentos com nove repetições, sendo cada repetição correspondente a uma tora, totalizando 180 toras. Os dados foram submetidos à análise de variância e as médias, comparadas pelo teste de Tukey a 5\% de probabilidade (SNEDECOR e COCHRAN, 1972).

Inicialmente, de cada espécie e clone de eucalipto foram selecionadas ao acaso seis árvores, totalizando 60 [( 7 espécie +3 clones de eucalipto) x 6 árvores]. Essas árvores foram abatidas, retirarando de cada uma três discos em alturas distintas com $2,5 \mathrm{~cm}$ de espessura. Para tanto, com o auxílio de uma suta foram delimitados dois extremos em cada árvore, um com 9 e outro com $14 \mathrm{~cm}$ de diâmetro, de onde foi removido um disco por extremidade. O terceiro disco foi retirado do meio dessa área delimitada. Dessa forma, o total de discos coletados foi 180 [( 7 espécies +3 clones de eucalipto) x 6 árvores $\mathrm{x} 3$ discos], os quais foram identificados ainda no campo. Posteriormente cada disco foi dividido em quatro cunhas com ângulo de $90^{\circ}$ entre si, sendo a primeira cunha utilizada para a determinação da composição química e as demais, guardadas como reserva.

Logo após a retirada de cada disco, também foram cortadas toras de $1 \mathrm{~m}$ de comprimento do mesmo local de onde foram removidos os discos, ou seja, foram retiradas três toras por árvore em alturas distintas $(9 \mathrm{~cm}$, meio e $14 \mathrm{~cm})$, sempre após o corte dos discos. As toras foram identificadas ainda no campo para que, após a inoculação das linhagens de L. edodes, pudesse ser feito o acompanhamento das alterações químicas e físicas provocadas pelo fungo nas diferentes espécies e clones de eucalipto. Assim, das seis árvores abatidas por tipo de eucalipto, três foram destinadas à obtenção de nove toras para a inoculação da linhagem LE-96/ 18 e as outras três árvores para se obterem de nove toras para a inoculação dalinhagem LE-95/01 do L. edodes.

A inoculação das toras foi feita conforme a metodologia citada por Minhoni et al. (2007).

$\mathrm{Na}$ fase de incubação, as toras foram levadas a uma estufa, onde permaneceram por seis meses. Aestufa possuía dimensão de 20 x 10 m (comprimento x largura), cobertura de plástico leitoso (150 micras), laterais compostas por sombrite $(70 \%)$ e cortinas de plástico leitoso com opção de abertura e fechamento. Metade da estufa foi utilizada para incubação, sendo a outra metade reservada para a fase de produção de basidiomas. Os dois ambientes foram delimitados por plástico leitoso (150 micras).
As toras foram dispostas em três pilhas com 60 toras cada. A distribuição das 180 toras nas pilhas foi inteiramente ao acaso. Em cada pilha, as toras foram dispostas em 10 níveis de seis toras cada, num total de 80 toras. Os níveis de toras de cada pilha tiveram direções diferentes, de modo que níveis consecutivos formaram um ângulo de $90^{\circ}$ entre si.

As toras foram mantidas úmidas, através de irrigação diária por microaspersores de alta vazão $\left(15 \mathrm{~L} \mathrm{~h}^{-1}\right)$ e também de forma manual, quando necessário, utilizando-se mangueira de jardim. O monitoramento da temperatura e da umidade relativa do ar foi feito por meio de termoigrômetros instalados em três pontos diferentes da estufa. A umidade relativa do ar foi mantida elevada (60 - 80\%). Quanto à temperatura, esta se situou a $25 \pm 5{ }^{\circ} \mathrm{C}$.

A indução para a formação de basidiomas e colheita seguiu a mesma metodologia citada por Minhoni et al. (2007). No total foram feitas quatro induções, resultando, durante o ciclo produtivo do L. edodes, em quatro fluxos de produção.

Para a determinação das análises químicas da madeira foram utilizadas cunhas de madeira coletadas logo após o corte das árvores e com oito meses de incubação, com o micélio das linhagens de L. edodes.

Inicialmente, foram retiradas as cascas das cunhas para análise individual de ambas. Na sequência, três cunhas de cada árvore (coletadas de alturas distintas da árvore: $9 \mathrm{~cm}$, meio e $14 \mathrm{~cm}$ ) foram agrupadas e reduzidas manualmente a cavacos e, depois, a palitos, constituindo 60 amostras de madeira e 60 amostras de casca, as quais foram utilizadas na determinação do teor de extrativos totais, lignina e holocelulose. Finalmente, as amostras foram reduzidas à serragem em macro moinho Wiley. A serragem obtida foi classificada em vibrador Produtest, para obtenção da fração 40/60 mesh. Portanto, as amostras de madeira e casca utilizadas nas análises químicas foram compostas de cunhas obtidas em alturas distintas das árvores. Assim, foram avaliadas 240 amostras: 120 provenientes de discos de árvores coletados logo após o corte (60 amostras de madeira e 60 amostras de casca) e 120 coletadas de discos de toras provenientes dessas mesmas árvores após oito meses de incubação com as linhagens de L. edodes (60 amostras de madeira e 60 amostras de casca).

R. Árvore, Viçosa-MG, v.34, n.1, p.165-175, 2010 
Tabela 1 - Análises efetuadas da avaliação de extrativos totais, lignina e holocelulose.

Table 1 - Analyses performed to evaluate total extractives, lignin and hollocelulose.

\begin{tabular}{cc}
\hline Extrativos totais & TAPPI T $264 \mathrm{~cm}-97$ \\
Lignina Klason & TAPPI T 222 om -83 \\
Holocelulose & $100-\%$ Extrativos totais \\
& $-\%$ Lignina \\
\hline
\end{tabular}

As análises de extrativos totais, lignina e holocelulose foram feitas de acordo com as análises citadas na Tabela 1, no Departamento de Recursos Naturais - Laboratório de Análises Químicas - FCA/ UNESP.

\section{RESULTADOS E DISCUSSÃO}

Na Tabela 2, encontram-se os valores de F obtidos na análise de variância dos dados de holocelulose, lignina e extrativos totais da madeira (sem a casca) após o corte em função do fator tipo de eucalipto (7 espécies e 3 clones). Houve efeito significativo do tipo de eucalipto em todas as variáveis analisadas. O coeficiente de variação mostra baixos valores para holocelulose e lignina e valor elevado para extrativos totais, indicando ampla variação dessa última análise.

A Tabela 3 mostra os valores de F obtidos na análise de variância dos dados de holocelulose, lignina e extrativos totais da madeira (sem a casca) depois de oito meses de incubação em função dos fatores tipos de eucalipto ( 7 espécies e 3 clones) e linhagens de L. edodes (LE-95/01 e LE-96/18) e interação entre eles. Houve efeito significativo somente do tipo de eucalipto em todas as variáveis analisadas.

A Figura 1 mostra a comparação de médias de holocelulose da madeira (sem a casca) de 10 tipos de eucalipto, após o corte (parte superior) e depois de oito meses de incubação com o L. edodes (parte inferior). As maiores médias das madeiras após o corte foram observadas no clone 23, E. grandis, clone 25, clone 24, E. paniculata e E. citriodora. No entanto, as menores médias foram observadas no E. camaldulensis, E. urophylla e E. pellita. Gonzaga et al. (1983) relataram valores mais elevados de holocelulose em E. grandis $(74,7 \%)$ e E. urophylla $(74,1 \%)$ e valores inferiores em E. camaldulensis $(70,9 \%)$ e E. pellita (72,8\%). Miranda e Barrichelo (1990) mostraram maior teor de holocelulose na madeira de E. citriodora $(74,7 \%)$ em relação ao E. saligna $(72,8 \%)$. As maiores médias das madeiras depois de oito meses de incubação com o L. edodes foram obtidas no clone 23, E. grandis, clone 25, clone 24, E. paniculata e E. citriodora. Entretanto, as menores médias foram observadas no $E$. pellita, $E$. saligna, E. urophylla e no E. camaldulensis. Nas toras de todos os tipos de eucaliptos, verificou-se que suas

Tabela2 - Valores de F obtidos na análise de variância de holocelulose, lignina e extrativos totais da madeira (sem a casca) de sete espécies (E. saligna, E. grandis, E. urophylla, E. pellita, E. paniculata, E. citriodora e E. camaldulensis) e três clones (híbridos de $E$. urophylla x E. grandis) de eucalipto após o corte.

Table $2-F$ values obtained from analysis of variance for hollocelulose, lignin and total extractives of wood (without bark) of seven species (E. saligna, E. grandis, E. urophylla, E. pellita, E. paniculata, E. citriodora and E. camaldulensis) and three clones (E. grandis $x$ E. urophylla hybrids) of eucalyptus after cutting.

\begin{tabular}{cccc}
\hline $\begin{array}{l}\text { Fonte de } \\
\text { Variação }\end{array}$ & Holocelulose & Lignina & $\begin{array}{c}\text { Extrativos } \\
\text { Totais }\end{array}$ \\
\hline Eucalipto & $10,12^{*}$ & $13,61^{*}$ & $4,04^{*}$ \\
DMS & 3,58 & 2,66 & 2,34 \\
CV $(\%)$ & 2,55 & 5,80 & 48,24 \\
\hline
\end{tabular}

*Significativo a 1\% (Tukey, p>0,05: DMS = Diferença Mínima Significativa; e CV = Coeficiente de Variação).

Tabela 3 - Valores de F obtidos da análise de variância de holocelulose, lignina e extrativos totais da madeira (sem a casca) de sete espécies (E. saligna, E. grandis, E. urophylla, E. pellita, E. paniculata, E. citriodora e E. camaldulensis) e três clones (híbridos de $E$. urophylla x E. grandis) de eucalipto após oito meses de incubação com as linhagens LE-95/01 e LE-96/18 de L. edodes.

Table 3 - F values from analysis of variance for hollocelulose, lignin and total extractives of wood (without bark) of seven species (E. saligna, E. grandis, E. urophylla, E. pellita, E. paniculata, E. citriodora and E. camaldulensis) and three clones (E. urophylla $x$ E. grandis hybrids) of eucalyptus after 8 months of incubation with the strains LE-95/01 and LE96/18 of L. edodes.

\begin{tabular}{cccc}
\hline $\begin{array}{c}\text { Fonte de } \\
\text { Variação }\end{array}$ & Holocelulose & Lignina & $\begin{array}{c}\text { Extrativos } \\
\text { Totais }\end{array}$ \\
\hline Eucalipto (E) & $5,82^{*}$ & $7,08^{*}$ & $2,49 * *$ \\
Fungo (F) & $1,16^{\text {ns }}$ & $2,68^{\mathrm{ns}}$ & $0,20^{\mathrm{ns}}$ \\
E x F & $1,38^{\mathrm{ns}}$ & $1,53^{\mathrm{ns}}$ & $1,02^{\mathrm{ns}}$ \\
DMS (E) & 5,09 & 3,96 & 3,40 \\
CV $(\%)$ & 3,68 & 8,37 & 40,51 \\
\hline
\end{tabular}

*Significativo a $1 \%$; **significativo a 5\%; e ns: não significativo (Tukey, p>0,05: DMS = Diferença Mínima Significativa; e $\mathrm{CV}=$ Coeficiente de Variação). 
médias iniciais foram reduzidas após oito meses de cultivo, evidenciando a degradação da holocelulose na nutrição fúngica. O decréscimo pôde ser mais notado em $E$. saligna, E. pellita e E. citriodora. Já em E. camaldulensis essa redução de média de holocelulose ao longo do tempo foi relativamente menor. A comparação da composição química das madeiras após o corte e depois de oito meses de incubação com o L. edodes deve ser analisada com cautela, pois as bases de cálculo são diferentes, uma base é madeira sadia e a outra é base da madeira com certo grau de degradação.

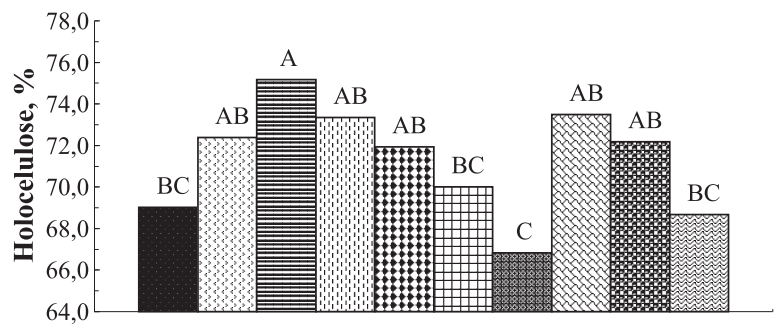

Espécies e clones de eucalipto

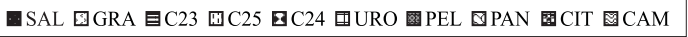

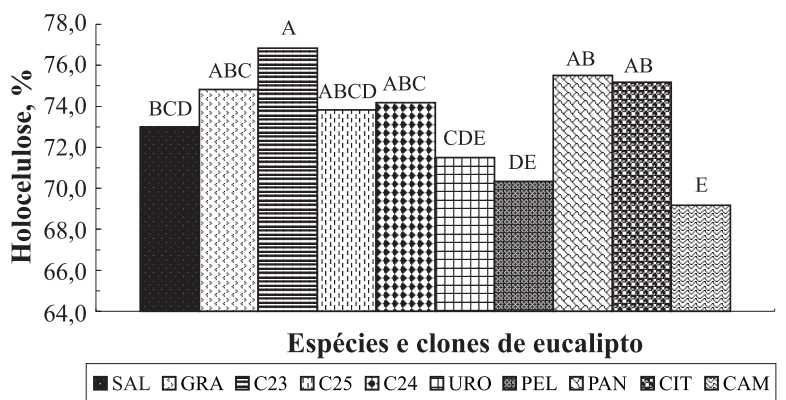

Figura 1 - Holocelulose da madeira sem a casca de E. saligna (SAL), E. grandis (GRA), clone 23 (C23), clone 25 (C25), clone 24 (C24), E. urophylla (URO), E. pellita (PEL), E. paniculata (PAN), E. citriodora (CIT) e de E. camaldulensis (CAM) após o corte e depois de oito meses de incubação com o L. edodes. Médias com letras iguais não diferem entre si (Tukey, $5 \%$ ). Os clones 23,24 e 25 são híbridos de $E$. grandis $\mathrm{x}$ E. urophylla.

Figure 1 - Hollocelulose from wood without bark of E. saligna (SAL), E. grandis (GRA), clone 23 (C23), clone 25 (C25), clone 24 (C24), E. urophylla (URO), E. pellita (PEL), E. paniculata (PAN), E. citriodora (CIT) and of E. camaldulensis (CAM) after cutting and after 8 months of incubation with L. edodes. Means with same letters are not significantly different (Tukey, 5\%). Clones 23, 24 and 25 are hybrid of E. grandis $x$ E. urophylla.
A Figura 2 mostra a comparação de médias de lignina da madeira (sem a casca) de 10 tipos de eucalipto, após o corte (parte superior) e depois de oito meses de incubação com L. edodes (parte inferior). As maiores médias das madeiras após o corte foram observadas no E. camaldulensis e no E. pellita. No entanto, as menores médias foram observadas no E. citriodora, E. grandis, clone 23, clone 25 e E. paniculata. Gonzaga et al. (1983) encontraram, também, teores mais elevados de lignina em E. camaldulensis e E. pellita $(29,2 \%$ e $27,6 \%$, respectivamente) quando comparados com
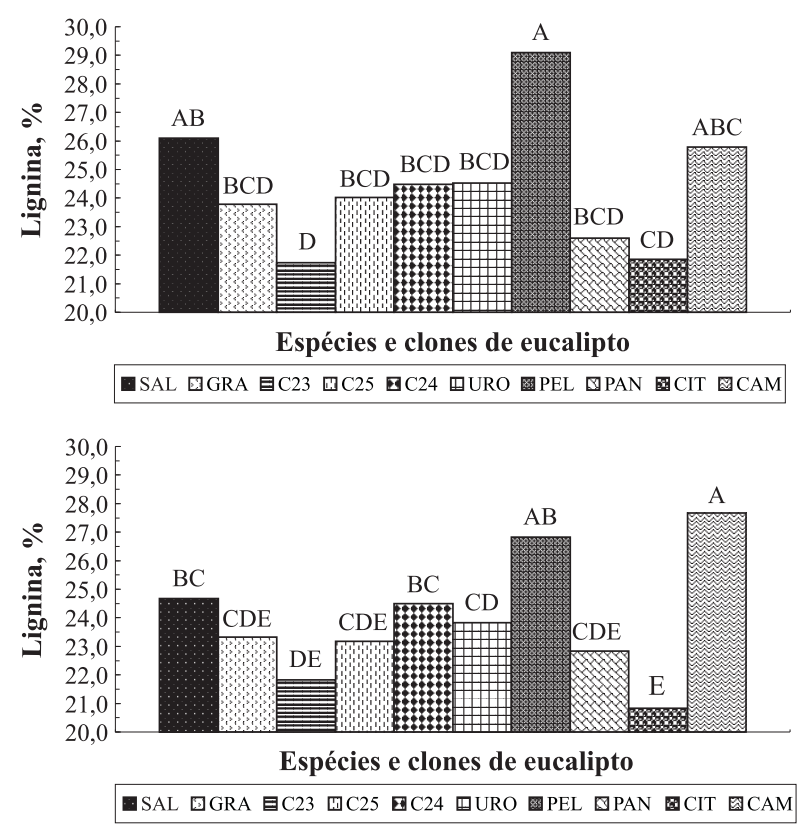

Figura 2 - Lignina da madeira sem a casca de E. saligna (SAL), E. grandis (GRA), clone 23 (C23), clone 25 (C25), clone 24 (C24), E. urophylla (URO), E. pellita (PEL), E. paniculata (PAN), E. citriodora (CIT) e de E. camaldulensis (CAM) após o corte e depois de oito meses de incubação com o $L$. edodes. Médias com letras iguais não diferem entre si (Tukey, 5\%). Os clones 23, 24 e 25 são híbridos de E. grandis x E. urophylla.

Figure 2-Lignin from wood without bark (in percentage) of E. saligna (SAL), E. grandis (GRA), clone 23 (C23), clone 25 (C25), clone 24 (C24), E. urophylla (URO), E. pellita (PEL), E. paniculata (PAN), E. citriodora (CIT) and of E. camaldulensis (CAM) after cutting and after 8 months of incubation with L. edodes. Means with same letters are not significantly different (Tukey, 5\%). Clones 23, 24 and 25 are hybrid of E. grandis $x$ E. urophylla.

R. Árvore, Viçosa-MG, v.34, n.1, p.165-175, 2010 
E. saligna, E. urophylla e E. grandis $(26,8 \%, 26,8 \%$ e $23,4 \%$, respectivamente) aos 4,5 anos de idade. Foelkel et al. (1975) mostraram teores de lignina crescente na seguinte ordem: E. citriodora (7 anos) $<$ E. paniculata (6 anos) < E. saligna (8 anos). Miranda e Barrichelo (1990) relataram menor teor de lignina em E. citriodora - 6 anos (19,6\%) em relação ao E. saligna -5 anos $(23,3 \%)$. As maiores médias das madeiras depois de oito meses de incubação com $L$. edodes foram observadas no E. pellita, E. saligna e E. camaldulensis. No entanto, as menores médias foram observadas no E. grandis, clone 23, clone 25, clone 24, E. urophylla, E. paniculata e E. citriodora. O teor de lignina na madeira após oito meses de incubação com o L. edodes foi mais elevado quando comparado com a madeira após o corte, em vários tipos de eucaliptos. Isso aconteceu, principalmente, nas madeiras de E. saligna, E. pellita e E. citriodora, que foram aquelas que apresentaram maior redução no teor de holocelulose. Então, a madeira degradada apresentou maior teor de lignina, proporcionalmente, que a madeira sadia. A madeira é composta, sobretudo, por celulose e hemiceluloses que juntas formam a fração da madeira denominada holocelulose, a qual está envolta numa matriz de lignina (RAYNER e BODDY, 1988). Tanto a holocelulose quanto a lignina são constituídas exclusivamente de carbono, hidrogênio e oxigênio e servem como fontes de energia e carbono para o crescimento fúngico. Crestini et al. (1998) demonstraram que L. edodes é capaz de degradar a lignina, exercendo efeito positivo no crescimento e formação do basidioma.

A Figura 3 mostra a comparação de médias de extrativos totais da madeira (sem a casca) de 10 tipos de eucalipto, após o corte (parte superior) e depois de oito meses de incubação com L. edodes (parte inferior). As maiores médias das madeiras após o corte foram observadas no E. urophylla e no E. citriodora. Médias intermediárias foram observadas no E. saligna, clone 25, E. pellita, E. paniculata e E. camaldulensis. As menores médias foram observadas no $E$. grandis, clones 23 e clone 24. As médias das madeiras depois de oito meses de incubação com o L. edodes não diferiram significativamente. Os extrativos são compostos químicos acidentais considerados não essenciais para a estrutura das paredes celulares e lamela média (BARRICHELO e BRITO, 1976). No entanto, alguns de seus componentes (óleos essenciais, graxas, ceras e taninos, entre outros), em proporções elevadas, podem influenciar o crescimento do L. edodes, uma vez que, como já relatado por Pettersen (1984), alguns deles podem apresentar efeito antifúngico.
Observou-se que os teores de extrativos totais na madeira de oito meses de incubação foram superiores aos da madeira após o corte dos diversos tipos de eucalipto. Esse resultado mostra pouca alteração no teor de extrativos totais. Os valores de extrativos totais mais elevados na madeira degradada são devidos ao decréscimo do teor de holocelulose dessa madeira.

No Tabela 4, encontram-se os valores de F obtidos na análise de variância dos dados de holocelulose, lignina e extrativos totais da casca após o corte em função do fator tipo de eucalipto (7 espécies e 3 clones). Houve efeito significativo do tipo de eucalipto em todas as variáveis analisadas.

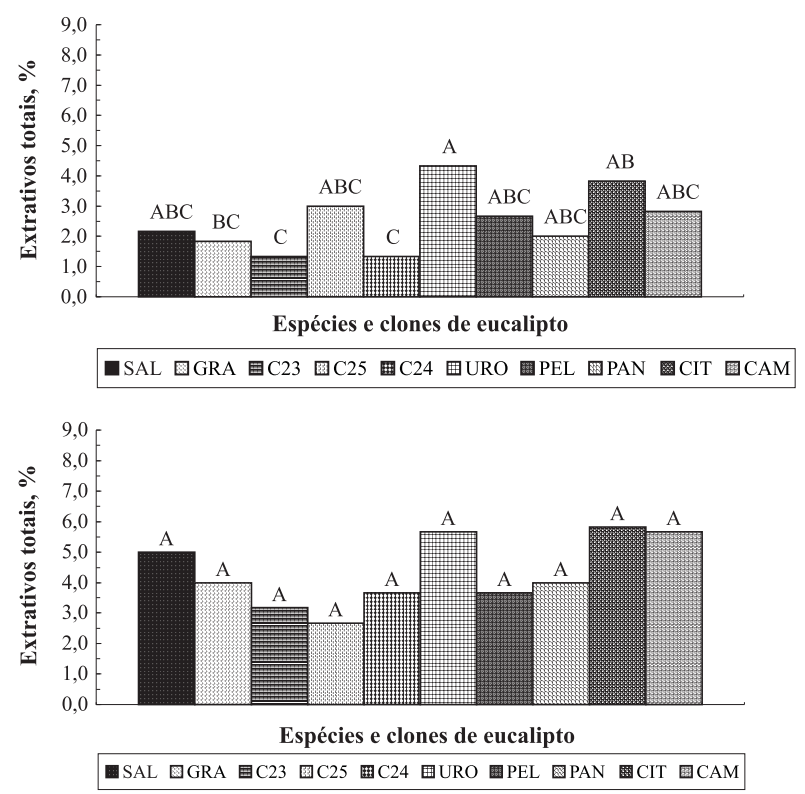

Figura 3-Extrativos totais da madeira sem a casca de $E$. saligna (SAL), E. grandis (GRA), clone 23 (C23), clone 25 (C25), clone 24 (C24), E. urophylla (URO), E. pellita (PEL), E. paniculata (PAN), E. citriodora (CIT) e de E. camaldulensis (CAM) após o corte e depois de oito meses de incubação com o L. edodes. Médias com letras iguais não diferem entre si (Tukey, $5 \%$ ). Os clones 23, 24 e 25 são híbridos de $E$. grandis $\mathrm{x}$ E. urophylla.

Figure 3 - Total extractives from wood without bark of E. saligna (SAL), E. grandis (GRA), clone 23 (C23), clone 25(C25), clone 24(C24), E. urophylla (URO), E. pellita (PEL), E. paniculata (PAN), E. citriodora (CIT) and of E. camaldulensis (CAM) after cutting and after 8 months of incubation with L. edodes. Means with same letters are not significantly different (Tukey, 5\%). Clones 23, 24 and 25 are hybrid of E. grandis $x$ E. urophylla. 
Tabela 4 - Valores de F obtidos da análise de variância de holocelulose, lignina e extrativos totais da casca de sete espécies (E. saligna, E. grandis, E. urophylla, E. pellita, E. paniculata, E. citriodora e E. camaldulensis) e três clones (híbridos de E. urophylla $\mathrm{x}$ E. grandis) de eucalipto após o corte.

Table $4-F$ values from analysis of variance for hollocelulose, lignin and total extractives of bark of seven species (E. saligna, E. grandis, E. urophylla, E. pellita, E. paniculata, E. citriodora and E. camaldulensis) and three clones (E. grandis $x$ E. urophylla hybrids) of eucalyptus after cutting.

\begin{tabular}{cccc}
\hline Fonte de & Holocelulose & Lignina & $\begin{array}{c}\text { Extrativos } \\
\text { Totais }\end{array}$ \\
Variação & & & $2,15^{* *}$ \\
\hline Eucalipto & $13,88^{*}$ & $25,90^{*}$ & 6,27 \\
DMS & 6,67 & 4,89 & 51,76 \\
CV $(\%)$ & 5,12 & 10,09 & 5 \\
\hline
\end{tabular}

*Significativo a $1 \%$; e **significativo a $5 \%$ (Tukey, p>0,05: DMS = Diferença Mínima Significativa; e CV = Coeficiente de Variação).

O Tabela 5 mostra os valores de F obtidos na análise de variância dos dados de holocelulose, lignina e extrativos totais da casca depois de oito meses de incubação em função dos fatores tipos de eucalipto ( 7 espécies e 3 clones) e linhagens de L. edodes (LE-95/01 e LE-96/18) e interação entre eles. Verificou-se que houve efeito significativo do tipo de eucalipto em todas as variáveis analisadas e do tipo de fungo na variável lignina.

A Figura 4 mostra a comparação de médias de holocelulose da casca de 10 tipos de eucalipto, após o corte (parte superior) e depois de oito meses de incubação com o L. edodes (parte inferior). As maiores médias das madeiras após o corte foram observadas no E. grandis, clone 23, clone 24, E. citriodora, E. camaldulensis, E. saligna, clone 25 e no E. urophylla. No entanto, a menor média foi observada no E. paniculata. Assim, embora a lignina e a holocelulose possam ser utilizadas pelo fungo durante o seu metabolismo, a lignina é, porém, o elemento que limita a acessibilidade dos polissacarídeos do ataque por enzimas hidrolíticas (CRAWFORD, 1981; ERIKSSON et al., 1990). As maiores médias das madeiras depois de oito meses de incubação com o L. edodes foram observadas no E. citriodora e no E. grandis. Médias intermediárias foram observadas no clone 23 , clone 25 , clone $24, E$. urophylla e E. camaldulensis. Finalmente, as menores médias foram obtidas no E. saligna, E. pellita e $E$. paniculata. O teor de holocelulose da casca após oito meses de incubação com o L. edodes foi muito inferior quando comparado com a casca após o corte dos vários tipos de eucaliptos. A visualização das Figuras 4 e 1 mostra que o teor de holocelulose na casca foi inferior ao encontrado na madeira após o corte, exceto em E. camaldulensis (partes superiores das Figuras 4 e 1). Vital et al. (1989) encontraram menor teor de holocelulose na casca em relação à madeira de E. grandis com 9 anos de idade. O teor de holocelulose na casca após o corte foi consideravelmente reduzido, para todos os tipos de eucalipto analisados, em relação à casca após oito meses de cultivo com o L. edodes (Figura 4). Comparando com o decréscimo do teor de holocelulose observado na madeira (Figura 1), fica evidente a importância da casca na colonização do fungo disponibilizando nutrientes, além de que a casca também funciona como barreira física que protege a madeira, já que ela está em contato direto com o ambiente e todas as suas variações.

Tabela 5 - Valores de F obtidos da análise de variância de holocelulose, lignina e extrativos totais da casca de sete espécies (E. saligna, E. grandis, E. urophylla, E. pellita, E. paniculata, E. citriodora e E. camaldulensis) e três clones (híbridos de E. urophylla x E. grandis) de eucalipto, após oito meses de incubação com as linhagens LE-95/01 e LE-96/ 18 de L. edodes.

Table 5 - F values from analysis of variance for hollocelulose, lignin and total extractives of bark of seven species (E. saligna, E. grandis, E. urophylla, E. pellita, E. paniculata, E. citriodora and E. camaldulensis) and three clones (E. urophylla $x$ E. grandis hybrids) of eucalyptus after 8 months of incubation with the strains LE-95/01 and LE-96/18 of L. edodes.

\begin{tabular}{cccc}
\hline $\begin{array}{c}\text { Fonte de } \\
\text { Variação }\end{array}$ & Holocelulose & Lignina & $\begin{array}{c}\text { Extrativos } \\
\text { Totais }\end{array}$ \\
\hline Eucalipto (E) & $3,63^{*}$ & $23,54^{*}$ & $3,64^{*}$ \\
Fungo (F) & $3,19^{\mathrm{ns}}$ & $9,48^{*}$ & $0,22^{\mathrm{ns}}$ \\
E x F & $0,63^{\mathrm{ns}}$ & $0,97^{\mathrm{ns}}$ & $0,58^{\mathrm{ns}}$ \\
DMS (E) & 11,70 & 5,72 & 11,83 \\
DMS (F) & - & 1,54 & - \\
CV $(\%)$ & 10,27 & 13,20 & 32,29 \\
\hline
\end{tabular}

*Significativo a 1\%; e ns: não significativo (Tukey, p>0,05: DMS = Diferença Mínima Significativa; e CV = Coeficiente de Variação).

R. Árvore, Viçosa-MG, v.34, n.1, p.165-175, 2010 


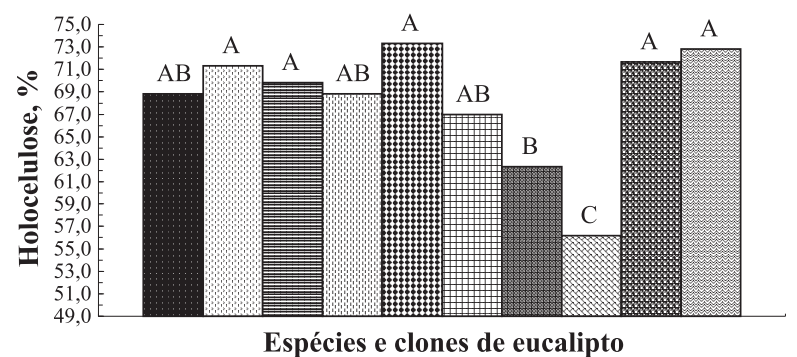

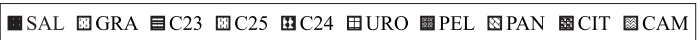

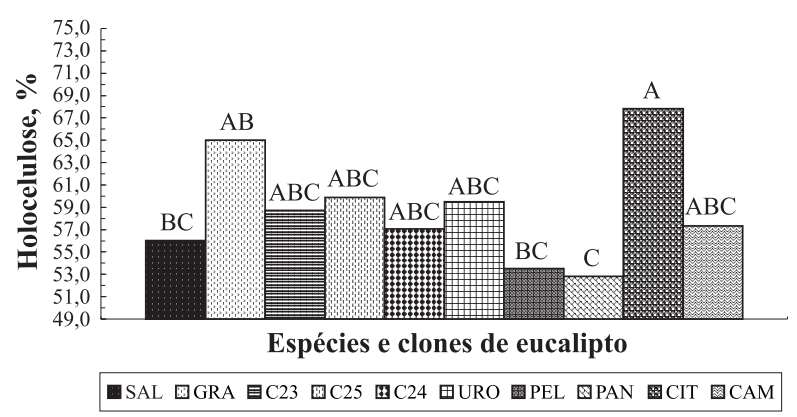

Figura 4-Holocelulose da casca de E. saligna (SAL), E. grandis (GRA), clone 23 (C23), clone 25 (C25), clone 24 (C24), E. urophylla (URO), E. pellita (PEL), E. paniculata (PAN), E. citriodora (CIT) e de E. camaldulensis (CAM) após o corte e depois de oito meses de incubação com o L. edodes. Médias com letras iguais não diferem entre si (Tukey, $5 \%$ ). Os clones 23, 24 e 25 são híbridos de E. grandis $x$ E. urophylla.

Figure 4-Hollocelulose from bark of E. saligna (SAL), E. grandis ( GRA), clone 23 (C23), clone 25 (C25), clone 24 (C24), E. urophylla (URO), E. pellita (PEL), E. paniculata (PAN), E. citriodora (CIT) and of E. camaldulensis (CAM) after cutting and after 8 months of incubation with L. edodes. Means with same letters are not significantly different (Tukey, 5\%). Clones 23, 24 and 25 are hybrid of E. grandis $x$ E. urophylla.

A Figura 5 mostra a comparação de médias de lignina da casca de 10 tipos de eucalipto, após o corte (parte superior) e depois de oito meses de incubação com o L. edodes (parte inferior). A maior média das madeiras após o corte foi observada no E. paniculata. No entanto, as menores médias foram observadas no E. saligna, E. grandis, clone 23, clone 25, clone 24, E. urophylla, E. citriodora e E. camaldulensis. As maiores médias das madeiras depois de oito meses de incubação com o L. edodes foram observadas no E. pellita e no E. paniculata. Entretanto, as menores médias foram observadas no E. grandis, clone 24, E. saligna, clone 23, clone 25, E. citriodora e E. camaldulensis. A comparação das Figuras 5 e 2 mostra que o teor de lignina na casca pode ser semelhante (E. saligna, E. grandis e clones), superior (E. pellita, E. paniculata e E. citriodora) ou inferior ( $E$. camaldulensis) ao encontrado na madeira após o corte (partes superiores das Figuras 5 e 2). Vital et al. (1989) encontraram teor de lignina inferior na casca em relação à madeira de E. grandis. O teor de lignina na casca após corte foi reduzido, em todos os tipos de eucalipto analisados, em relação à casca após oito meses de cultivo com o L. edodes (Figura 4), indicando preferência do L. edodes pela lignina da casca.
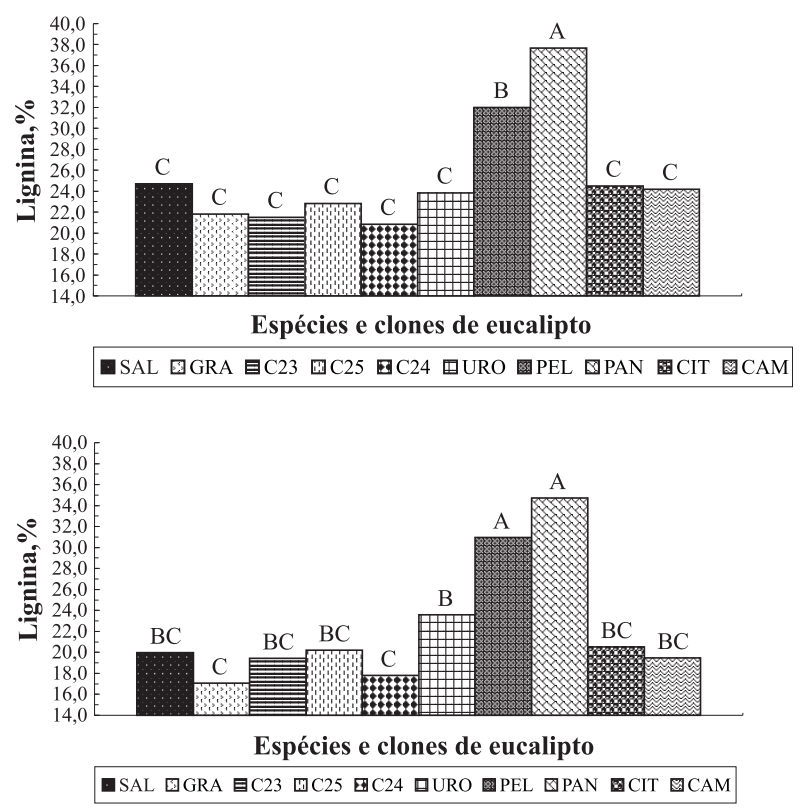

Figura 5 - Lignina da casca de E. saligna (SAL), E. grandis (GRA), clone 23 (C23), clone 25 (C25), clone 24 (C24), E. urophylla (URO), E. pellita (PEL), E. paniculata (PAN), E. citriodora (CIT) e de E. camaldulensis (CAM) após o corte e depois de oito meses de incubação com o L. edodes. Médias com letras iguais não diferem entre si (Tukey, $5 \%$ ). Os clones 23, 24 e 25 são híbridos de $E$. grandis x E. urophylla.

Figure 5-Lignin from bark of E. saligna (SAL), E. grandis (GRA), clone 23 (C23), clone 25 (C25), clone 24 (C24), E. urophylla (URO), E. pellita (PEL), E. paniculata (PAN), E. citriodora (CIT) and of E. camaldulensis (CAM) after cutting and after 8 months of incubation with L. edodes. Means with same letters are not significantly different (Tukey, 5\%). Clones 23, 24 and 25 are hybrid of E. grandis $x$ E. urophylla. 
A Figura 6 mostra a comparação de médias de extrativos totais da casca de 10 tipos de eucalipto, após o corte (parte superior) e depois de oito meses de incubação com o L. edodes (parte inferior). Não houve diferença significativa das médias de extrativos totais das madeiras após o corte em função do tipo de eucalipto. As maiores médias das madeiras depois de oito meses de incubação com o L. edodes foram observadas no clone 24 e no E. saligna. Médias intermediárias foram observadas no $E$. grandis, clone 23, clone 25, E. urophylla, E. pellita e E. camaldulensis.
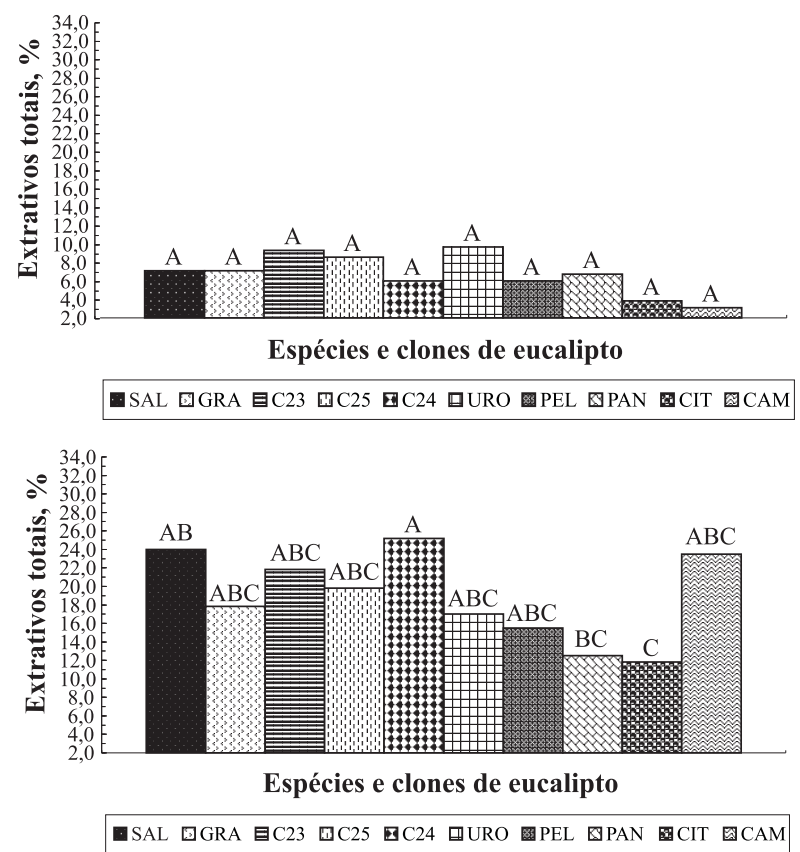

Figura 6 - Extrativos totais da casca de E. saligna (SAL), E. grandis (GRA), clone 23 (C23), clone 25 (C25), clone 24 (C24), E. urophylla (URO), E. pellita (PEL), E. paniculata (PAN), E. citriodora (CIT) e de E. camaldulensis (CAM) após o corte e depois de oito meses de incubação com o L. edodes. Médias com letras iguais não diferem entre si (Tukey, $5 \%$ ). Os clones 23, 24 e 25 são híbridos de E. grandis $\mathrm{x}$ E. urophylla.

Figure 6-Total extractives from bark of E. saligna (SALT), E. grandis (GRA), clone 23 (C23), clone 25 (C25), clone 24 (C24), E. urophylla (URO), E. pellita (PEL), E. paniculata (PAN), E. citriodora (CIT) and of E. camaldulensis (CAM) after cutting and after 8 months of incubation with L. edodes. Means with same letters are not significantly different (Tukey, 5\%). Clones 23, 24 and 25 are hybrid of E. grandis $x$ E. urophylla.
Finalmente, as menores médias foram observadas no E. citriodora e no E. paniculata. A comparação das Figuras 6 e 3 mostra que o teor de extrativos totais na casca foi superior ao encontrado na madeira após o corte (partes superiores das Figuras 6 e 3). Vital et al. (1989) obtiveram teores de extrativos da casca sensivelmente mais elevados do que aqueles encontrados em madeira de E. grandis com 9 anos de idade. O teor de extrativos totais na casca após o corte foi consideravelmente mais elevado, em todos os tipos de eucalipto analisados, em relação à casca após oito meses de cultivo com o L. edodes (Figura 4). Esse resultado é atribuído aos decréscimos observados nos teores de holocelulose da casca (Figura 4) e lignina da casca (Figura 5).

A Figura 7 mostra a comparação de médias do teor de lignina da casca do eucalipto (independente do tipo) em função do tipo de linhagem de L. edodes inoculada, após oito meses de incubação. A maior média foi observada na casca do eucalipto sob influência da linhagem LE-95/01 de L. edodes. De acordo com esses resultados, há diferenças da eficiência degradativa da casca entre as linhagens LE-95/01 e LE-96/18 de $L$. edodes. No entanto, a degradação de lignina só é importante para o crescimento fúngico se disponibilizar para os fungos acesso ao nitrogênio contidos nos componentes da madeira (BOYLE, 1998).

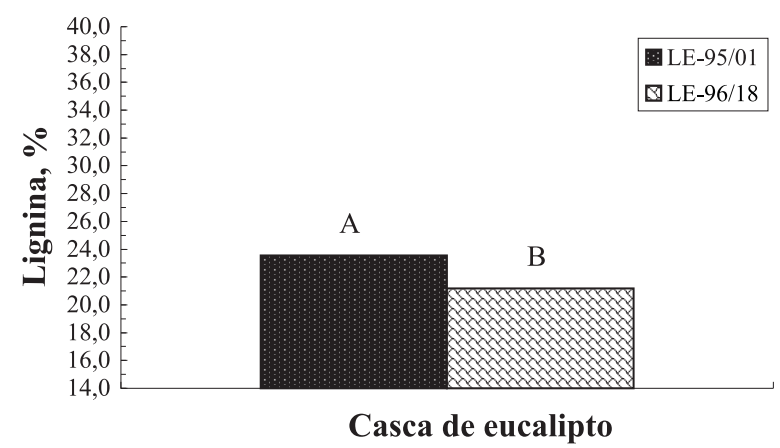

Figura 7 - Teor de lignina da casca de eucalipto, independente do tipo, após oito meses de incubação com o $L$. edodes, em função da linhagem de L. edodes inoculada. Médias com letras iguais não diferem entre si (Tukey, $5 \%$ ). Os clones 23,24 e 25 são híbridos de $E$. grandis $\mathrm{x}$ E. urophylla.

Figure 7 - Lignin content in eucalyptus bark, independent of type, after 8 months of incubation with L. edodes, as a function of the inoculated strain of $L$. edodes. inoculated (Tukey, 5\%). Clones 23, 24 and 25 are hybrid of E. grandis $x$ E. urophylla.

R. Árvore, Viçosa-MG, v.34, n.1, p.165-175, 2010 


\section{CONCLUSÃO}

Os resultados permitiram as seguintes conclusões:

Houve diferenças significativas nos teores de holocelulose, lignina e extrativos totais das madeiras dos diferentes tipos de eucalipto após o corte. As cascas dessas madeiras apresentaram diferenças em relação à holocelulose e lignina.

O maior índice de decomposição da holocelulose na madeira, ao longo do tempo, ocorreu no E. saligna $(5,5 \%)$, indicando assim, ser o mais favorável para o desenvolvimento micelial do L. edodes. Já na casca aconteceu no clone $24(22,2 \%)$.

O E. camaldulensis apresentou o maior índice de decomposição da lignina na madeira $(6,8 \%)$, ao longo do tempo. Já na casca, entre os eucaliptos testados, o E. grandis sofreu a maior decomposição de lignina $(21,9 \%)$.

As madeiras dos diferentes tipos de eucalipto após oito meses de incubação com L. edodes apresentaram diferenças significativas nos teores de holocelulose e lignina. Foram detectadas diferenças significativas nos três componentes químicos avaliados nas cascas dessas madeiras.

O L. edodes degradou muito mais a holocelulose e lignina da casca que da madeira tornando evidente a importância da casca na colonização desse fungo.

A casca da maioria dos tipos de eucaliptos apresentou menor teor de holocelulose, maior teor de extrativos totais e teores de lignina semelhantes ou superiores quando comparados com a madeira.

O fator tipo de eucalipto (espécies e clones) teve maior efeito que o fator linhagem de L. edodes na degradação de holocelulose e lignina.

\section{REFERÊNCIAS}

ANDRADE, M. C. N. Crescimento micelial, produção e características bromatológicas do shiitake em função de linhagens e de propriedades físicas e químicas de espécies e clones de eucalipto. 2007. 195f. Tese (Doutorado em Agronomia/Energia na Agricultura) - Universidade Estadual Paulista, Botucatu, 2007.

R. Árvore, Viçosa-MG, v.34, n.1, p.165-175, 2010
ANDRADE, M. C. N. et al. Avaliação do crescimento micelial de linhagens de shiitake, da produção em toras de eucalipto e de alterações físicas da madeira. Acta Scientiarum, v.29, n.1, p.23-27, 2007.

ANDRADE, M. C. N.; GRACIOLLI, L. A. Controle de fungos contaminantes no cultivo do cogumelo comestível shiitake em toros de eucalipto. Acta Scientiarum, v.27, n.2, p.293-299, 2005.

BARRICHELO, L. E. G.; FOELKEL, C. E. B. Estudo para produção de celulose sulfato de seis espécies de eucalipto. IPEF, n.12, p.77-95, 1976.

BARRICHELO, L. E. G.; BRITO, J. O.

Potencialidade de espécies tropicais de eucalipto para produção de celulose sulfato branqueada. IPEF, n.13, p.9-37, 1976.

BOYLE, C. D. Nutritional factors limiting the growth of Lentinula edodes and other white-rot fungi in wood. Soil Biology \&

Biochemistry, v.30, p.817-823, 1998.

BROWNING, B. L. The chemistry of wood. New York: John Wiley \& Sons, 1963. 689p.

CHEN, A. W. What is shiitake? In: GUSH, R. (Ed.). Shiitake cultivation. Korea: MushWord, 2005. p.3-32.

CRAWFORD, R. L. Lignin biodegradation and transformation. New York: Wiley, 1981. 154p.

CRESTINI, C.; SERMANNI, G.; ARGYROPOULOS, D. Structural modifications induced during biodegradation of wheat lignin by Lentinula edodes. Bioorganic and Medicinal Chemistry Letters, v.6, p.967-973, 1998.

EIRA, A. F.; MONTINI, R. M. C. Manual teórico prático de cultivo de cogumelo Shiitake (Lentinula edodes (Berk.)

Pegler). Botucatu: Fundação de Estudos e Pesquisas Agrícolas e Florestais, 1997. 38p.

ERIKSSON, K.-E.; BLANCHETTE, R. A.; ANDER, P. Microbial and enzymatic degradation of wood and wood components. Berlin: Springer-Verlag, 1990. 416p. 
FOELKEL, C. E. B.; BARRICHELO, L. E. G.; MILANEZ, A. F. Estudo comparativo das madeiras de Eucalyptus saligna, E. paniculata, E. citriodora, E. maculata e E. tereticornis para produção de celulose sulfato. IPEF, n.10, p.1737, 1975.

GONZAGA, J. V. et al. Qualidade da madeira e da celulose Kraft branqueada de treze espécies de Eucalyptus. In: CONGRESSO LATINOAMERICANO DE CELULOSE E PAPEL, 3., 1983, São Paulo. Resumos... São Paulo: ABTCP, 1983. p.7-29.

MINHONI, M. T. A. et al. Cultivo de Lentinula edodes (Berk.) Pegler (Shiitake). 3.ed. Botucatu: FEPAF, 2007. 91p.

MIRANDA, C. R.; BARRICHELO, L. E. G. Celulose de madeira de E. citriodora: influência do tamanho de cavacos. In: CONGRESSO ANUAL DA ABTCP, 23., 1990, São Paulo. Resumos... São Paulo: ABTCP, 1990. p.1-34.

MOnTINI, R. M. C. Produtividade de shiitake (Lentinula edodes (Berk.) Pegler), no primeiro choque de indução, em função de características dos toros do Eucalyptus saligna, Sm, variáveis do ambiente e período de incubação. 1997. 61f. Dissertação (Mestrado em Agronomia/Energia na Agricultura) - Universidade Estadual Paulista, Botucatu, 1997.

PETTERSEN, R. C. The chemical composition of wood. In: ROWELL, R. (Ed.). The chemistry of solid wood. Washington: American Chemical Society, 1984. p.54-126.

PRZYBYLOWICZ, P.; DONOGHUE, J. L. edodes grower's handbook: the art and science of mushroon cultivation. Dubuque: Kendall, 1990. 217p.

RAYNER, A. D. M.; BODDY, L. Fungal decomposition in wood: it is biology and ecology. New York: John Wiley, 1988. 587p.
QUEIROZ, E. C. Efeito da suplementação mineral na conversão de energia e produtividade do Shiitake em toros de eucalipto. 2002. 73f. Dissertação (Mestrado em Agronomia/Energia na Agricultura) - Universidade Estadual Paulista, Botucatu, 2002.

SILVA, J. C. Eucalipto: pesquisa amplia usos: perspectivas do setor florestal brasileiro. Revista da Madeira, v.13, n.75, p.4-6, 2003.

SNEDECOR, G. W. E.; COCHRAN, W. G.

Statistical methods. 6.ed. Ames: Iwoa State University Press, 1972. 325p.

SOUZA, A. P.; DELLA LUCIA, R. M.; RESENDE, G. C. Estudo da densidade básica da madeira de Eucalyptus microcorys. F. Muell, cultivado na região de Dionísio, MG. Revista Árvore, v.3, n.1, p.16-27, 1979.

TECHNICAL ASSOCIATION OF THE PULP AND PAPER INDUSTRY - TAPPI. Normas

técnicas. Atlanta: 1999. Preparation of wood for chemical analysis, norma TAPPI T 264 cm-97. Acid insoluble lignin in wood and pulp, norma TAPPI T 222 om-83.

TEIXEIRA, E. M. Caracterização isoenzimática e molecular de Lentinula edodes e avaliação da produção em função da espécie de eucalipto e clima. 2000. 123f. Tese (Doutorado em Biotecnologia/Biotecnologia) - Universidade Estadual Paulista, Araraquara, 2000.

TREVISAN, H. et al. Avaliação de propriedades físicas e mecânicas da madeira de cinco espécies florestais em função da deterioração em dois ambientes. Revista Árvore, v.31, n.1, p.93$101,2007$.

TOKIMOTO, K. Shiitake log cultivation. In: GUSH, R. (Ed.). Shiitake cultivation. Korea: MushWord, 2005. p.56-87.

VITAL, B. R. et al. Influência da casca no rendimento e na qualidade do carvão vegetal de Eucalyptus grandis. IPEF, n.41/42, p.44-49, 1989. 
